\title{
Manual aspiration thrombectomy through balloon tipped guide catheter for rapid clot burden reduction in endovascular therapy for ICA $L / T$ occlusion
}

\author{
Kannath Santhosh $\cdot$ Santhosh Joseph
}

Received: 30 June 2012 / Accepted: 12 July 2012 /Published online: 27 July 2012

(C) Springer-Verlag 2012

Dear Sir,

We have read with great interest the article of Eesa $\mathrm{M}$ et al. describing the manual aspiration technique for internal carotid artery (ICA) occlusions with large clot burden after achieving temporary flow arrest with a balloon-tipped guide catheter [1]. This technique is very useful in situations where there is large clot burden or when the clot is refractory to approved mechanical thrombectomy devices. Large clot burden has been correlated with prolonged procedural time, reduced recanalisation, and poor clinical outcome [2]. In this context, it is worthwhile to attempt this technique especially when the thrombus burden is known from imaging studies. An important issue is the timing of this procedure, as initial attempts may not yield a consistent result or complicates the procedure and later attempts prolong the procedure surpassing the window period. It is unclear whether the authors have employed this technique after the standard mechanical thrombectomy options are exhausted.

We would like to report to the authors a modification of their technique. We encountered a patient with an Acom aneurysm who developed thromboembolic occlusion of the right supraclinoid ICA following placement of the guiding catheter. Since the aneurysm was ruptured, the administration

\footnotetext{
K. Santhosh $(\bowtie)$

Department of Imaging Sciences and Interventional Radiology, Sri Chitra Institute of Medical Sciences and Technology, 695011, Trivandrum, Kerala, India

e-mail: santhoshkannath@rediffmail.com

S. Joseph

Department of Neuroradiology, Sri Ramachandra Medical College and Research Institute,

600116, Chennai, India
}

of intraarterial thrombolytics could be dangerous. Moreover, mechanical devices were not available to us at that time. We attempted manual aspiration of the clot through the guiding catheter after occluding the carotid artery by manual compression. This resulted in the aspiration of partial clot, with opening of anterior cerebral artery and migration of clot into the middle cerebral artery. The aneurysm was promptly coiled and thrombolytics were administered in the middle cerebral artery. The clot was refractory and the patient later underwent decompressive craniectomy. This technique may be useful when the clot cannot be removed by standard options and balloontipped guiding catheters are unavailable, especially in situations limited by financial constraints.

The authors are to be congratulated for describing a technique that might improve the outcome chances when all the options are exhausted. However, one should keep in mind the possibility of nontarget embolization of the clot with this technique especially when it is situated beyond the ICA bifurcation. This can seriously affect the outcome of the patient if the collateral vessels are occluded.

Conflict of interest We declare that we have no conflict of interest.

\section{References}

1. Eesa M, Almekhlafi MA, Mitha AP, Wong JH, Goyal M (2012) Manual aspiration thrombectomy through balloon-tipped guide catheter for rapid clot burden reduction in endovascular therapy for ICA L/T occlusion. Neuroradiology. doi:10.1007/s00234-012-1039-3

2. Barreto AD, Albright KC, Hallevi H, Grotta JC, Noser EA, Khaja AM, Shaltoni HM, Gonzales NR, Illoh K, Martin-Schild S, Campbell MS 3rd, Weir RU, Savitz SI (2008) Thrombus burden is associated with clinical outcome after intra-arterial therapy for acute ischemic stroke. Stroke 39:3231-3235 